\title{
Need for multi-scale systems to identify spindle orientation regulators relevant to tissue disorganization in solid cancers
}

\author{
Hui Men Selina Chin ${ }^{\dagger}$, Karandeep Nandra ${ }^{\dagger}$, Joanna Clark and Viji M. Draviam * \\ Department of Genetics, Cancer Cell Biology, University of Cambridge, Cambridge, UK \\ ${ }^{*}$ Correspondence: viji.draviam@gen.cam.ac.uk \\ these authors have contributed equally to this work.
}

Edited by:

Akatsuki Kimura, National Institute of Genetics, Japan

Reviewed by:

Akatsuki Kimura, National Institute of Genetics, Japan

Fumiko Toyoshima, Kyoto University, Japan

Keywords: cell division, cancer inititation, cancer progression, spindle orientation, Hippo pathway, microtubules, Wnt pathway, PTEN regulation

\section{INTRODUCTION}

During cell division, the mitotic spindle captures chromosomes and segregates them into two equal sets. The orientation and position of the mitotic spindle is important because the spindle equator becomes the plane of cell division. For instance, in a columnar cell with apical and basal polarity, if the spindle pole-to-pole axis orients along the cell's long axis, the cell will divide along its short-axis; however, if the spindle axis orients along the cell's short axis, the cell will divide along its long-axis (Figure 1A). Similarly when the spindle is off-centered (mis-positioned), it results in asymmetric cell sizes in the two daughter cells, which is often used to control tissue organization (Figure 1B). Thus, errors in the orientation and positioning of the mitotic spindle can cause incorrect plane of cell division leading to incorrect cell size, content and neighborhood of daughter cells (Figures 1A,B).

A human body experiences over a trillion divisions and through age errors in cell division can accumulate; errors in spindle orientation can contribute to tissue disorganization, a hallmark of several age-related conditions and also, carcinogenesis. However, mutations in classical cortical force generators that rotate the spindle to the correct orientation have not been shown to promote carcinogenesis. In contrast, several proteins known to play a role in cancer initiation and progression are being newly identified as regulators of spindle positioning and orientation. In this opinion article, we briefly discuss the surprising lack of direct evidence for classical spindle rotation regulators in oncogenesis and present examples of oncogenic pathway components that influence spindle orientation. We conclude with the need for new strategies to uncover the contribution of spindle orientation defects to tissue disorganization commonly found in cancers and also ageing disorders.

\section{A WEAK CASE FOR CORTICAL FORCE GENERATORS IN CANCER INITIATION}

For a detailed review on the mechanisms of spindle positioning and orientation, we recommend a recent review from Kulukian and Fuchs (2013). Astral microtubules of the spindle (Figure 1C) are pulled at and this rotates the entire spindle to a predefined position. Forces to pull the astral microtubules can arise from the cortex or within the cytoplasm, although classical evolutionarily conserved players have been reported at the cell cortex (reviewed McNally, 2013). Cortical pulling forces are essential for mitotic spindle positioning and orientation in human cells (see next para). Although it is very likely that compromising cortical pulling forces would lead to tissue disorganization and carcinogenesis, cortical force generator mutations are not prevalent in tumors and their genetic loss-of-function in mice do not present tumors (reviewed in Noatynska et al., 2012).

Dynein is the key player in cortical force generation and its localization is controlled by the cortical platform consisting of $\mathrm{G} \alpha_{\mathrm{i}}, \mathrm{LGN}$, and NuMA (Figure 1C) (Kiyomitsu and Cheeseman, 2012; Kotak et al., 2012; Corrigan et al., 2013). Considering that LGN is the primary platform for cortical dynein recruitment and absolutely essential in epithelial cells for biased rotation of the spindle (Corrigan et al., 2013), one would expect a more severe phenotype than the reported epidermal stratification defects in LGN depleted mouse skin (Williams et al., 2011). An explanation for this paradox can be gleaned from proliferation and cell death studies: First, LGN mutant mice lacking LGN's C-terminus are viable, but compromised for planar spindle orientation in the brain (Konno et al., 2008). This shows that the control of spindle orientation is essential for maintaining a population of neuroepithelial cells, but is dispensable for proliferative or differentiative decisions. In support of this idea, loss of Par3, a polarity protein that forms a complex with Par6/aPKC and controls spindle orientation (Hao et al., 2010), promotes breast tumorigenesis and metastasis, only in combination with oncogenic Notch or Ras (61L) expression (McCaffrey et al., 2012). Second, combining defects in cell death and spindle alignment disrupts epithelial integrity and causes tumor-like masses (Nakajima et al., 2013). Thus, spindle orientation defects and resulting cell fate defects could be resolved by other cell number control pathways (for example, cell proliferation and cell death), which indicates a cooperative role for orientation defects in tissue disorganization and 


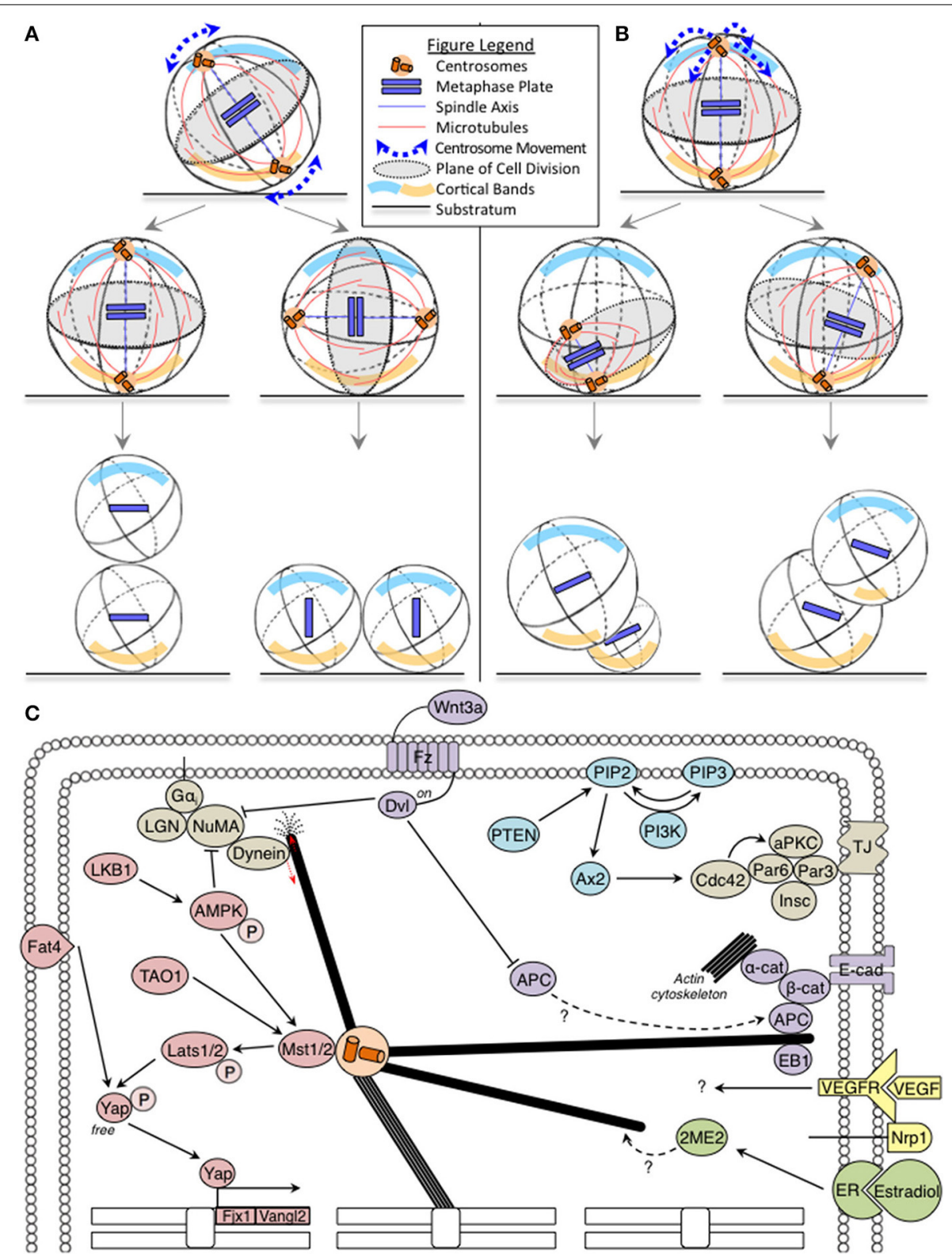

FIGURE 1 | (A,B) Fates of incorrect spindle orientation and positioning: Cartoons show mitotic spindle movements relative to the substratum leading to spindle mis-orientation (A) and mis-positioning (B) with cortical bands highlighting polarity differences. In (A), misorientation alters the relative positions and contents of daughter cells, without affecting progenitor cell sizes. In (B), mispositioning affects daughter cell size, relative positions and their contents. Legend describing cell substratum, spindle microtubules, metaphase plate, and spindle movements included. (C) Oncogenic pathways implicated in spindle orientation: The Hippo, PTEN-PI3K, and Wnt tumor suppressor pathway components are marked in pink, blue, and purple, respectively. The oncogenic estrogen receptor (ER) pathway is marked in green. Together, these pathways regulate astral microtubule (marked in bold) function. Red arrows indicate force generation events. The Hippo pathway also influences transcriptional regulation of several genes involved in orientation (marked on chromosomes). cancer progression, rather than cancer initiation per se.

\section{KEY ONCOGENIC PATHWAYS}

IMPLICATED IN SPINDLE ORIENTATION

While mutations in cortical force generators present a weak case for orientation defects leading to carcinogenesis, emerging evidence show a role for oncogenic and tumor suppressor pathways in ensuring spindle orientation. Three key examples are:

\section{Hippo tumor suppressor pathway}

The Hippo pathway is disrupted in a variety of cancers (reviewed in Harvey et al., 2013). Fat4, a member of the Hippo pathway in vertebrates (Skouloudaki et al., 2009) orients the plane of cell division to maintain the planar cell polarity (PCP) of elongating tubules during kidney development and prevents cyst formation common to ageing kidneys (Saburi et al., 2008; Mao et al., 2011). Fat4 regulates the expression of Vangl2 and Fjx1 (Saburi et al., 2008), which 
are asymmetrically localized Wnt-Fz PCP components (Montcouquiol et al., 2006). Recent additions to the Hippo pathway, LKB1 tumor suppressor (Mohseni et al., 2014), AMPK (Thaiparambil et al., 2012) and TAO1 kinase (Poon et al., 2011) are also YAP regulators that act on Lats1 and MST2, and are important for mitosis and spindle orientation (Wojtala et al., 2011; Wei et al., 2012; Shrestha et al., 2014). It is currently unclear how Fat4, TAO1, LKB1 and the Hippo pathway link spindle orientation and tissue maintenance (Figure 1C), which is an important topic to be addressed.

\section{PTEN-PI3K signaling pathway}

The Phosphatase and tensin homolog deleted on chromosome 10 (PTEN) that regulates the PI3K-Akt-mTOR pathway are among the most frequently inactivated tumor suppressor genes in sporadic cancers (reviewed in Chalhoub and Baker, 2009). PI3K influences spindle orientation in non-polarized cells (Toyoshima et al., 2007). PTEN deficiency impairs glandular morphogenesis, through Ax2 and Cdc42, leading to abnormal multi-luminal phenotypes (Martin-Belmonte et al., 2007; Jagan et al., 2013). Thus, loss of PTENPI3K signaling can result in incorrectly oriented daughter cells, which may be of relevance to PTEN-associated tissue disorganization common to geriatric conditions and carcinogenesis.

\section{Wnt signaling pathway}

Multiple components of Wnt pathway are known to control spindle orientation. First, spatial restriction of Wnt3a is sufficient to align the spindle parallel to the axis of cell polarity and induce asymmetrical cell division leading to asymmetrical inheritance of Wnt signaling components. This provides a mechanism for extrinsic control of cell fate and differentiation (Habib et al., 2013), but its specific role in cancer is unclear. Second, APC, a Wnt pathway member, is a tumor suppressor and regulator of microtubule stability and cell polarity (Zumbrunn et al., 2001; Etienne-Manneville and Hall, 2003). APC and its interactors, EB1 (a microtubuleend binding protein) and $\beta$-catenin are all needed for stable spindle positioning
(Draviam et al., 2006; Wu et al., 2010 and reviewed in Tamura and Draviam, 2012). While inactivation of both APC alleles is required for carcinogenesis (reviewed in Reya and Clevers, 2005), loss of a single allele is sufficient for spindle misorientation (Fleming et al., 2009). It is unclear if APC's role in spindle orientation and Wnt signaling converge in preventing carcinogenesis (Figure 1C). However, APC is known to bind $\beta$-catenin, which together with E-cadherin and $\alpha$-catenin, are actin regulators with a role in spindle orientation (reviewed in Allan and Näthke, 2001). Third, Dvl is another component of the Wnt-PCP pathway which influences spindle orientation (Ségalen et al., 2010), and its role in linking spindle orientation with carcinogenesis is also not known.

In summary, studies of PTEN, Hippo and Wnt tumor suppressor pathways show evidence for more than one protein of any single pathway being involved in spindle orientation (Figure 1C). Whether their role in spindle orientation is important for their tumor suppressor function is not known and is an important question to address.

\section{EXCITING FUTURE DIRECTIONS FOR ELUCIDATING HOW DEFECTIVE SPINDLE ORIENTATION IS LINKED TO TISSUE DISORGANIZATION IN AGEING DISORDERS AND CANCERS}

Multiple lines of evidence show the co-existence of spindle orientation failure and growth dysregulation. Is this a mere coincidence? Alternatively, does this co-existence play any role in tissue disorganization seen in cancers or ageing disorders? To help address these questions, two approaches are going to be pivotal:

\section{Multi-scale imaging (Single-cell and tissue-level studies: two sides of a coin)}

Multi-scale systems that capture single-cell and tissue level information are crucial to track the emergence of tissue-level defects (growth dysregulation) from single-cell errors (spindle orientation failure). For instance, in cancer stem cells of skin papilloma, the inhibition of VEGF alters the ratio of symmetric:asymmetric cell divisions causing tumor regression (Beck et al., 2011). How VEGF and its coreceptor Nrp1 influence the plane of cell division is unclear (Figure 1C); and establishing this may very well require single-cell studies of the perivascular niche Cancer Stem Cells exposed to tumorcell derived VEGF. In some cases, tissuespecific organotypic models (such as the 3D cyst model; Durgan et al., 2011) amenable to single-cell tracking may be sufficient. For example, chronic estrogen application is linked to hyperplasia and cancer: estrogen increases symmetric cell division (Gunin et al., 2001), and an estrogen metabolite, 2-methoxy estradiol (2ME), alters microtubule dynamics and disrupts spindle orientation (Corrigan et al., 2013). Determining how sub-cellular microtubule perturbation ultimately manifests into changes in symmetric vs. asymmetric cell division rates in tissues could be addressed using organotypic models that can recapitulate estradiol-dependent morphogenesis.

\section{A quantitative way to define interme- diary dynamic steps of spindle orien- tation}

In cell cultures that have lost polarity and resemble those that have gone through Epithelial-Mesenchymal transition, even a small directional bias in moving the spindle toward the final destination is sufficient to achieve the correct orientation of the spindle (Corrigan et al., 2013)—what is the molecular basis of this robustness? Is this dependent on the microtubule -wall or -end interaction at the cell-cortex, similar to microtubule interaction geometries at chromosomes (Shrestha and Draviam, 2013)? Is this dependent exclusively on cortical pulling forces that act on microtubules or also on pushing forces of microtubules against the actin mesh-work, or forces generated by intracellular transport (reviewed in McNally, 2013). Addressing these in human cells will require us to consider the temporal evolution of various spindle movements and not simply the binary end-outcome of spindle orientation "failure" vs. "success." Examples of similar approach have been already fruitful in C.elegans (Pecreaux et al., 2006; Kimura and Onami, 2010). Finally, understanding the evolution of spindle movements is important because even a simple delay 
in spindle movements can increase the probability of spindle orientation defects, as human cells have not been reported to have a spindle orientation checkpoint so far.

\section{CONCLUSIONS}

Knowing the intermediary steps of the spindle orientation process can help reveal how growth regulatory pathways like the Hippo or mTOR pathway that receive various signals from developmental and stress cues, jointly regulate spindle movements. This along with multi-scale systems will be important for determining molecular lesions in spindle orientation and positioning which are frequently associated with tissue disorganization observed in ageing disorders and solid cancers.

\section{ACKNOWLEDGMENTS}

Viji M. Draviam is a Cancer Research UK career development fellow. We thank Prof. Frederick Campbell, Queens University, Belfast, UK and Dr. Noriko Hiroi, Keio University, Japan for insightful comments. We thank members of the Draviam laboratory, particularly Mr. Roshan Shrestha and Mr. Duccio Conti for help with proofreading the article.

\section{REFERENCES}

Allan, V., and Näthke, I. S. (2001). Catch and pull a microtubule: getting a grasp on the cortex. Nat. Cell Biol. 3, E226-E228. doi: 10.1038/ncb1001e226

Beck, B., Driessens, G., Goossens, S., Youssef, K. K., Kuchnio, A., Caauwe, A., et al. (2011). A vascular niche and a VEG-Nrp1 loop regulate the initiation and stemness of skin tumours. Nature 478, 399-403. doi: 10.1038/nature 10525

Boggiano, J., Vanderzalm, P., and Fehon, R. (2011). Tao-1 phosphorylates hippo/MST kinases to regulate the hippo-salvador-warts tumour suppressor pathway. Dev. Cell 21, 888-895. doi: 10.1016/j.devcel.2011.08.028

Chalhoub, N., and Baker, S. J. (2009). PTEN and the PI3-kinase pathway in cancer. Annu. Rev. Pathol. 4, 127-150. doi: 10.1146/annurev.pathol.4.110807. 092311

Corrigan, A. M., Shrestha, R. L., Zulkipli, I., Hiroi, N., Liu, Y., Tamura, N., et al. (2013). Automated tracking of mitotic spindle pole positions shows that LGN is required for spindle rotation but not orientation maintenance. Cell Cycle 12, 2643-2655. doi: $10.4161 /$ cc. 25671

Draviam, V. M., Shapiro, I., Aldridge, B., and Sorger, P. K. (2006). Misorientation and reduced stretching of aligned sister kinetochores promote chromosome missegregation in EB1- or APC-depleted cells. EMBO J. 25, 2814-2827. doi: 10.1038/sj.emboj.7601168
Durgan, J., Kaji, N., Jin, D., and Hall, A. (2011). Par6B and atypical PKC regulate mitotic spindle orientation during epithelial morphogenesis. J. Biol. Chem. 286, 12461-12474. doi: 10.1074/jbc.M110. 174235

Etienne-Manneville, S., and Hall, A. (2003). Cdc42 regulates GSK-3 $\beta$ and adenomatous polyposis coli to control cell polarity. Nature $421,753-756$. doi: 10.1038/nature01423

Fleming, E. S., Temchin, M., Wu, Q., Maggio-Price, L., and Tirnauer, J. S. (2009). Spindle misorientation in tumors from APCmin/+ mice. Mol. Carcinog. 48, 592-598. doi: 10.1002/mc.20506

Gunin, A. G., Mashin, I. N., and Zakharov, D. A. (2001). Proliferation, mitosis orientation and morphogenetic changes in the uterus of mice following chronic treatment with both estrogen and glucocorticoid hormones. J. Endocrinol. 169, 23-31. doi: 10.1677/joe.0.1690023

Habib, S. J., Chen, B., Tsai, F., Anastassiadis, K., Meyer, T., Betzig, E., et al. (2013). A localized wnt signal orients asymmetric stem cell division in vitro. Science 339, 1445-1448. doi: 10.1126/science.1231077

Hao, Y., Du, Q., Chen, X., Zheng, Z., Balsbaugh, J. L., Maitra, S., et al. (2010). Par3 controls epithelial spindle orientation by aPKC-Mediated phosphorylation of apical pins. Curr. Biol. 20, 1809-1818. doi: 10.1016/j.cub.2010.09.032

Harvey, K. F., Zhang, X., and Thomas, D. M. (2013). The Hippo pathway and human cancer. Nat. Rev. Cancer 13, 246-257. doi: 10.1038/nrc3458

Jagan, I. C., Deevi, R. K., Fatehullah, A., Topley, R., Eves, J., Stevenson, M., et al. (2013). PTEN phosphatase-independent maintenance of glandular morphology in a predictive colorectal cancer model system. Neoplasia 15, 1218-1230. doi: 10.1593/neo.121516

Kimura, A., and Onami, S. (2010). Modelling microtubule-mediated forces and centrosome positioning in caenorhabditis elegans embryos. Methods Cell Biol. 97, 437-453. doi: 10.1016/S0091-679X(10)97023-4

Kiyomitsu, T., and Cheeseman, I. M. (2012). Chromosome- and spindle-pole-derived signals generate an intrinsic code for spindle position and orientation. Nat. Cell Biol. 14, 311-317. doi: 10. 1038/ncb2440

Konno, D., Shioi, G., Shitamukai, A., Mori, A., Kiyonari, H., Miyata, T., et al. (2008). Neuroepithelial progenitors undergo LGNdependent planar divisions to maintain self-renewability during mammalian neurogenesis. Nat. Cell Biol. 10, 93-101. doi: 10.1038/ ncb1673

Kotak, S., Busso, C., and Gönczy, P. (2012). Cortical dynein is critical for proper spindle positioning in human cells. J. Cell Biol. 199, 97-110. doi: 10.1083/jcb.201203166

Kulukian, A., and Fuchs, E. (2013). Spindle orientation and epidermal morphogenesis. Philos. Trans. R. Soc. Lond. B 368, 20130016. doi: 10.1098/rstb.2013.0016

Mao, Y., Mulvaney, J., Zakaria, S., Yu, T., Morgan, K. M., Allen, S., Irvine, K. D., et al. (2011). Characterization of a Dchs1 mutant mouse reveals requirements for Dchs1-Fat 4 signaling during mammalian development. Development 138, 947-957. doi: 10.1242/dev.057166
Martin-Belmonte, F., Gassama, A., Datta, A., Yu, W., Rescher, U., Gerke, V., et al. (2007). PTENmediated apical segregation of phosphoinositides controls epithelial morphogenesis through Cdc42. Cell 128, 383-397. doi: 10.1016/j.cell.2006. 11.051

McCaffrey, L. M., Montalbano, J., Mihai, C., and Macara, I. G. (2012). Loss of the Par3 polarity protein promotes breast tumorigenesis and metastasis. Cancer Cell 22, 601-614. doi: 10.1016/j.ccr.2012. 10.003

McNally, F. (2013). Mechanisms of spindle positioning. J. Cell Biol. 200, 131-140. doi: 10.1083/jcb.201210007

Mohseni, M., Sun, J., Lau, A., Curtis, S., Goldsmith, J., Fox, V. L., et al. (2014). A genetic screen identifies an LKB1-MARK signalling axis controlling the hippo-YAP pathway. Nat. Cell Biol. 16, 108-117. doi: $10.1038 / \mathrm{ncb} 2884$

Montcouquiol, M., Sans, N., Huss, D., Kach, J., Dickman, J. D., Forge, A., et al. (2006) Asymmetric localization of Vangl2 and Fz3 indicate novel mechanisms for planar cell polarity in mammals. J. Neurosci. 26, 5265-5275. doi: 10.1523/JNEUROSCI.4680-05.2006

Nakajima, Y., Meyer, E. J., Kroesen, A., McKinney, S. A., and Gibson, M. C. (2013). Epithelial junctions maintain tissue architecture by directing planar spindle orientation. Nature 500, 359-362. doi: 10.1038/nature 12335

Noatynska, A., Gotta, M., and Meraldi, P. (2012). Mitotic spindle (DIS)orientation and DISease: cause or consequence? J. Cell Biol. 199, 1025-1035. doi: $10.1083 /$ jcb. 201209015

Pecreaux, J., Roper, J., Kruse, K., Julicher, F., Hyman, A., Grill, S., et al. (2006). Spindle oscillations during asymmetric cell division require a threshold number of active cortical force generators. Curr. Biol. 16, 2111-2122. doi: 10.1016/j.cub.2006. 09.030

Poon, C., Lin, J., Zhang, X., and Harvey, K. (2011). The sterile 20-like kinase tao-1 controls tissue growth by regulating the salvadorwarts-hippo pathway. Dev. Cell 21, 896-906. doi: 10.1016/j.devcel.2011.09.012

Reya, T., and Clevers, H. (2005). Wnt signalling in stem cells and cancer. Nature 434, 843-850. doi: 10.1038/nature03319

Saburi, S., Hester, I., Fischer, E., Pontoglio, M., Eremina, V., Gessler, M., et al. (2008). Loss of Fat4 disrupts PCP signaling and oriented cell division and leads to cystic kidney disease. Nat. Genet. 40, 1010-1015. doi: 10.1038/ng.179

Ségalen, M., Johnston, C. A., Martin, C. A., Dumortier, J. G., Prehoda, K. E., David, N. B., et al. (2010). The Fz-Dsh planar cell polarity pathway induces oriented cell division via Mud/NuMA in drosophila and zebrafish. Dev. Cell 19, 740-752. doi: 10.1016/j.devcel.2010.10.004

Shrestha, R. L., and Draviam, V. M. (2013). Lateral to end-on conversion of chromosome-microtubule attachment requires kinesins CENP-E and MCAK. Curr. Biol. 23, 1514-1526. doi: 10.1016/j.cub.2013.06.040

Shrestha, R. L., Tamura, N., Fries, A., Levin, N., Clark, J., and Draviam, V. M. (2014). TAO1 kinase maintains chromosomal stability by facilitating proper congression of chromosomes. Open Biol. 4:130108. doi: 10.1098/rsob.130108 
Skouloudaki, K., Puetz, M., Simons, M., Courbard, J., Boehlke, C., Hartleben, B., et al. (2009). Scribble participates in hippo signaling and is required for normal zebrafish pronephros development. Proc. Natl. Acad. Sci. U.S.A. 106, 8579-8584. doi: 10. 1073/pnas.0811691106

Tamura, N., and Draviam, V. M. (2012). Microtubule plus-ends within a mitotic cell are 'moving platforms' with anchoring, signalling and forcecoupling roles. Open Biol. 2:120132. doi: 10.1098/ rsob. 120132

Thaiparambil, J. T., Eggers, C. M., and Marcus, A. I. (2012). AMPK regulates mitotic spindle orientation through phosphorylation of myosin regulatory light chain. Mol. Cell. Biol. 32, 3203-3217. doi: 10.1128/MCB.00418-12

Toyoshima, F., Matsumura, S., Morimoto, H., Mitsushima, M., and Nishida, E. (2007). PtdIns(3,4,5)P3 regulates spindle orientation in adherent cells. Dev. Cell 13, 796-811. doi: 10. 1016/j.devcel.2007.10.014

Wei, C., Bhattaram, V. K., Igwe, J. C., Fleming, E., and Tirnauer, J. S. (2012). The LKB1 tumor suppressor controls spindle orientation and localization of activated AMPK in mitotic epithelial cells.
PLoS ONE 7:e41118. doi: 10.1371/journal.pone. 0041118

Williams, S. E., Beronja, S., Pasolli, H. A., and Fuchs, E. (2011). Asymmetric cell divisions promote notch-dependent epidermal differentiation. Nature 470, 353-358. doi: 10.1038/nature09793

Wojtala, R. L., Tavares, I. A., Morton, P. E., Valderrama, F., Thomas, N. S. B., and Morris, J. D. H. (2011). Prostate-derived Sterile 20-like kinases (PSKs/TAOKs) Are activated in mitosis and contribute to mitotic cell rounding and spindle positioning. J. Biol. Chem. 286, 30161-30170. doi: 10.1074/jbc.M111.228320

Wu, M., Smith, C. L., Hall, J. A., Lee, I., LubyPhelps, K., and Tallquist, M. D. (2010). Epicardial spindle orientation controls cell entry into the myocardium. Dev. Cell 19, 114-125. doi: 10.1016/j.devcel.2010.06.011

Zumbrunn, J., Kinoshita, K., Hyman, A. A., and Näthke, I. S. (2001). Binding of the adenomatous polyposis coli protein to microtubules increases microtubule stability and is regulated by GSK3 $\beta$ phosphorylation. Curr. Biol. 11, 44-49. doi: 10.1016/S0960-9822(01) 00002-1
Conflict of Interest Statement: The authors declare that the research was conducted in the absence of any commercial or financial relationships that could be construed as a potential conflict of interest.

Received: 16 May 2014; paper pending published: 20 June 2014; accepted: 08 July 2014; published online: 25 July 2014.

Citation: Chin HMS, Nandra K, Clark J and Draviam VM (2014) Need for multi-scale systems to identify spindle orientation regulators relevant to tissue disorganization in solid cancers. Front. Physiol. 5:278. doi: 10.3389/fphys.2014.00278

This article was submitted to Systems Biology, a section of the journal Frontiers in Physiology.

Copyright (C) 2014 Chin, Nandra, Clark and Draviam. This is an open-access article distributed under the terms of the Creative Commons Attribution License (CC BY). The use, distribution or reproduction in other forums is permitted, provided the original author(s) or licensor are credited and that the original publication in this journal is cited, in accordance with accepted academic practice. No use, distribution or reproduction is permitted which does not comply with these terms. 